\title{
Water Treatments and Root-Shoot Growth Relations in Yemane (Gmelina arborea roxb.) Seedlings
}

\author{
Robert T. Ngidlo \\ College of Advanced Education, Ifugao State University, Potia Campus, Alfonso Lista, Ifugao, Philippines
}

Email address:

r.ngidlo@gmail.com

To cite this article:

Robert T. Ngidlo. Water Treatments and Root-Shoot Growth Relations in Yemane (Gmelina arborea roxb.) Seedlings. Agriculture, Forestry and Fisheries. Vol. 5, No. 2, 2017, pp. 25-32. doi: 10.11648/j.ajaf.20170502.13

Received: July 11, 2016; Accepted: March 9, 2017; Published: April 2, 2017

\begin{abstract}
The nursery study was conducted to provide a scientific explanation for the practice of hardening seedlings in the nursery prior to out-planting in the open field. Three watering treatments (unstressed condition (US) seedlings watered twice a day, moderately stressed condition (MS), seedlings watered once a week, and severely stressed condition (SS), water is applied when seedlings show symptoms of mid-day wilting) were applied to Yemane seedlings (Gmelina arborea Roxb.) and their effects on root-shoot growth parameters were measured. Yemane was selected as the test species considering their massive use for reforestation in the Philippines. The experiment was laid in a Randomized Complete Block Design (RCBD) with each treatment replicated 6 times. Data was obtained for a period of four (4) months and the ANOVA for RCBD was used to test level of significance among the treatments. The Duncan's Multiple Range Test (DMRT) was used to compare treatment means. Shoot height, stem diameter, leaf area and shoot biomass and root length, root diameter, root density and root biomass were the parameters measured for above and below ground, respectively. Water treatments influence biomass partitioning responsible for the changes in seedling morphology and architecture. Seedlings in unstressed condition has bigger basal stem diameter, longer shoot length and wider leaf area. Furthermore, seedlings in unstressed condition obtained the largest volume of green shoot biomass but when ovendried has lighter weights, compared to the moderate and severely stressed seedlings. Severely stressed seedlings obtained the largest biomass gain in the number and length of lateral roots, root density, root biomass, root: shoot ratio and the production of a more fibrous root system. Water stress treatments suppressed the elongation of shoot parts but promotes increases in root parts. In the same manner, water treatments influenced source-sink relation between root and shoot parts wherein carbohydrates accumulates in the leaves and stem of seedlings in unstressed condition but shift to the roots in moderate and severely stressed condition. The shift in carbon allocation is an adaptive mechanism for stress regulation accounting for the larger increment in root parts under water stressed environment. It is clear that water stress treatments modified root and shoot morphology and it can used as a hardening tool for seedlings during the nursery tending phase.
\end{abstract}

Keywords: Water Stress, Water Treatment, Root Growth, Shoot Growth, Hardening Treatment

\section{Introduction}

Hardening of seedlings is a long established nursery management tradition in the Philippines. It is done by gradually exposing seedlings to sunlight and at the same time withdrawing the application of water several months before out-planting. Past experiences in the application of hardening treatments transformed succulent seedlings into hardened tissues that can withstand the harsh condition of the plantation area. In the Philippines most if not all plantation areas are located along the slopes with shallow and heavily marginalized soil conditions. These areas are predominantly occupied 1/ College of Agriculture and Forestry, Ifugao State University, Potia Campus, Alfonso Lista, Ifugao, 3608 Philippines by cogon (Imperata cylindrica) after many years of severe exposure to rain, soil erosion and repeated forest fires. The survival and growth of newly planted seedlings in these open areas are affected by low soil fertility and poor water retention capacity which often results to plantation failures. The availability of soil moisture a few days after outplanting may spell the success and doom of reforestation. Seedlings that are tailored to withstand these harsh environmental conditions has better chances of survival.

The study therefore is an attempt to understand how 
seedlings of Yemane (Gmelina arborea roxb.) respond to water treatments to provide a scientific basis for relating the practice of hardening treatments as a way of conferring better adaptation to seedlings. Yemane (Gmelina arborea Roxb.) was selected as the test species considering its popularity as a plantation crop in the Philippines. The study seek to understand the nature of root and shoot growth responses of yemane seedlings to water as a hardening tool. Specifically, the study aimed to: 1) identify root and shoot and growth responses of yemane to three levels of water treatments, 2) Identify compensatory growth patterns in response to water treatments, 3) Assessed carbon allocation patterns in response to water treatment and 4) Identify growth features that have implication and relevance to forest nursery management. The results of this study has practical relevance to forest nursery and plantation managers, silviculturist, plant propagators and community forestry stakeholders.

\section{Materials and Methods}

\subsection{Description of the Experimental Unit}

Half-sib seedlings of Yemane grown in the nursery of the Philippine Department of Environment and Natural Resources of Ifugao Province (DENR-Ifugao) were used in this study. Seedlings were taken and transferred to bigger sized plastic bags containing 4 liters of grassland soil-sand medium $(70: 30 \mathrm{v} / \mathrm{v})$ mixture and tended for two months to promote root development. Each of the pot was supplied uniformly with a tablespoonful of slow release fertilizer prior to the transfer of seedlings to hasten root development. The study was laid in a Randomized Complete Block Design (RCBD) with three watering treatment replicated six times. The nursery shed had a dimension of $4 \mathrm{~m} \times 6 \mathrm{~m}$ enough to contain all the treatments and shaded with green nylon nets to reduce the effect of direct sunlight and rain. The nursery shed was covered with transparent polyethylene roofing to prevent the intrusion of rain water inside the shed.

\subsection{Data Gathered}

The study focused on the measurement of treatment effects on seedling morphological traits on below and above ground parts. The determination of the carbohydrate contents of plant parts was also included in the study. The below ground parameters measured are: number, length and diameter of lateral roots, root density and root biomass. The above ground parameters are: stem diameter, shoot length, leaf area and aboveground biomass. The following parameters were obtained using the following:

\subsubsection{Diameter and Length of Lateral Roots}

Whole pots containing seedlings were dipped in a basin of tap water to loosen soil media. Roots were separated and cleaned. The diameter and length of lateral roots were measured using an engineers' caliper.

\subsubsection{Root Density}

Root density was measured using the water displacement method. Measurement was done by carefully lowering the roots still attached to the plant into a graduated cylinder with a known volume of water. The final volume less the initial volume displaced by the roots was recorded in cubic centimeters as the root density.

\subsubsection{Leaf Area}

Leaf samples were taken from the base, middle and top portion of seedling canopy every end of the month. Leaves were drawn in paper and a planimeter was passed through it to obtain the area in square centimeters.

\subsubsection{Stem Diameter and Height Growth}

Diameter and height growth was measured every end of the month. Since it is impossible to use seedlings of similar heights and diameter, the initial height and diameter were obtained at the start of the field experiment which provided the initial data for computing the height and diameter growth increment.

\subsubsection{Biomass Yield}

Each component plant part was separated then oven dried for its biomass expressed in dry dry weights.

\subsubsection{Carbohydrate Content of Plant Parts}

Carbohydrate content of plant parts were obtained at the end of the observation period and brought to the University of the Philippines, Los Baños for carbohydrate analysis.

\subsection{Experimental Design, Treatments and Analysis}

The study was laid in a Randomized Complete Block Design (RCBD) with three treatments replicated six times. The Analysis of Variance (ANOVA) was used to test significance among treatments. The Duncan's Multiple Range Test (DMRT) was used to compare treatment means. Three watering treatments were applied to seedlings for four months prior to destructive sampling. The watering treatment are:

\subsubsection{Unstressed Water Treatment}

Unstressed (US) - seedlings are watered every day at 8:00 in the morning and 5:00 in the afternoon. Two liters of water was applied to each seedling on a daily basis, one liter in the morning and one liter in the afternoon.

\subsubsection{Moderately Stressed Water Treatment}

Moderately stressed (MS)- the same amount of water is applied to seedlings in each pot once every week.

\subsubsection{Severely Stressed Water Treatment}

Severely Stressed (SS) - seedlings are watered only when it shows some indication of mid-day desiccation or wilting.

The seedling microcosm system developed by Friend et al. (1990) in their study on the effects of nutrient stress on root proliferation of Douglas fir seedlings was adopted in this study. The methodology simulated seedling growth planted on heterogeneous soil by segregating one major lateral root (approximately $10 \%$ of the root system) then allowing it to grow in a separate container. The microcosm approach is composed of pots of unequal volume. The large pot (4 liters) 
was used to measure the influence of water treatment on whole plant while the small pot (1 liter) was designed to measure individual root responses to water treatments with minimal effect on the main pot. Two seedlings are grown in each large pot, with one seedling in unstressed microenvironment while the other seedling on the opposite side is placed in stressed microenvironment. The methodology enabled the researcher to manipulate a portion of the root system with minimal or no effect on the main root system. The seedling microcosm system is shown below.

The Analysis of Variance (ANOVA) was used to determine differences among the treatments while the Duncan's Multiple Range Test (DMRT) was used to compare treatment means.
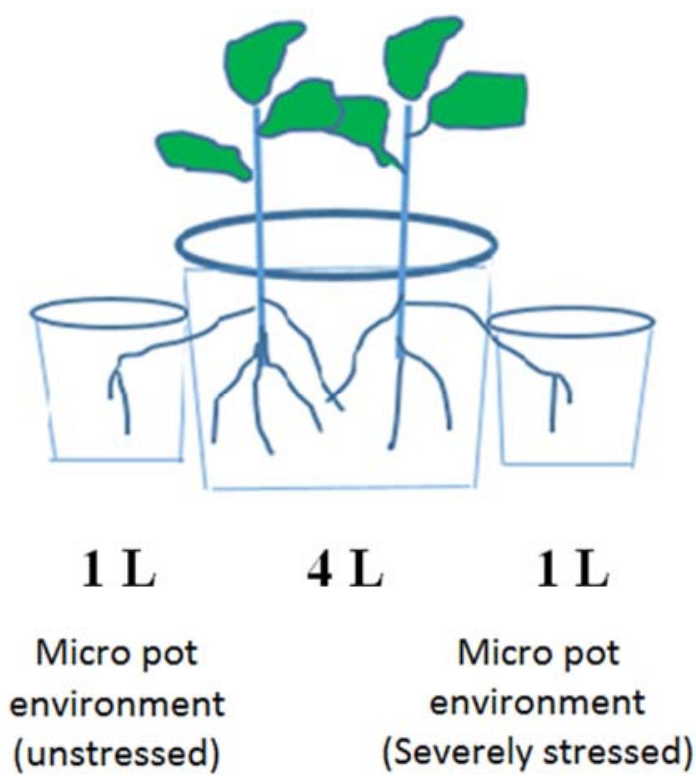

Figure 1. Seedling Microcosm system (Adopted from Friend et al. 1990).

\section{Results and Discussion}

Variations in the growth of shoot and root parts in seedlings grown in large pot.

At the end of the 4 months period, mean comparison by the Duncan's Multiple Range Test (DMRT) showed significant differences on the growth of shoot parts in terms of stem diameter, shoot length, leaf area and ovendried shoot biomass. For root parts, the same mean comparison by DMRT also showed significant differences in the number of lateral roots, root/shoot ratio and root biomass.

Water treatments influenced biomass partitioning in seedlings of Gmelina arborea roxb. The application of abundant water to seedlings (morning and afternoon) promotes the development of shoot parts. Well- watered seedlings are consistently taller in height with bigger stem and wider leaf area. Well-watered seedlings produced twice the volume of shoot biomass compared to the severely stressed seedlings. In contrast, severely stressed seedlings have smaller stem diameter, shorter shoot length, smaller leaf areas and smaller volume of shoot biomass. The shoot biomass of unstressed and severely stressed seedlings were found to differ in weights when ovendried. There is a bigger reduction in the ovendried biomass weights of wellwatered seedlings compared to the severely stressed seedlings. Perhaps this can be attributed to a higher water content in the tissues of well-watered shoot biomass which resulted to drastic losses in weights when ovendried. Auge et al. (1986) observed on rose plants differences in the shoot architecture of unstressed and severely stressed plants. Plants in severely stressed condition has shorter shoots with smaller stem and leaf area and this can be attributed to growth restrictions imposed by limited water supply. The longer shoot length obtained by well-watered seedlings can be attributed to the more favorable apical transport of nutrients and water from the soil to the shoot parts mediated by the availability of moisture in the tissues of plants.

Leaf area is always associated with photosynthesis and transpiration losses in plants. A wider leaf area provides greater surface available for photosynthesis and water loss by transpiration. According to Begg (1990) leaf area is one of the plant morphological trait that is highly sensitive to water stress and this is related to the limiting effects of water stress on cell growth. Osonubi and Fasehun (1987) observed that leaf extension in African Locust seedlings subjected to six two weeks cycles of soil drought declined relative to the wellwatered controlled plants, whereas relative root extension increased. The reduction of leaf area is an important parameter in regulating the effects of water stress. Begg (1990) cited that reduction in leaf area is associated with the reduction in water loss. The efficiency by which plant use water (WUE) is a major determinant of growth under water limited conditions (Korol et al. 1999). Reduction in leaf area is associated with the reduction in water loss providing a mechanism for reducing the rate of water use and delaying the onset of more stress on plants. Plants achieved high water use efficiency through either high net photosynthesis or low transpiration loss or both (Zhang et al. 1996). Plants with a higher water use efficiency have higher productivity or a greater ability to survive under stress than plants with a low water use efficiency.

Standard nursery practices should optimize the use of water to differentiate the growth and development of shoot parts. As shown in this study, the regulated application of water can reduce the diameter, shoot length and leaf area of seedlings. Shorter seedlings provide relative ease in seedling mobility especially in steep plantation areas. On the other hand, smaller leaf areas limits transpiration losses and increase the water use efficiency of seedlings thereby conveying better seedling survival.

If the targets for plantation establishment are fertile and well drained soils the sizes of seedlings (height and diameter) need not be reduce. Stem diameter (pencil size) and shoot length (at least $30 \mathrm{~cm}$ in height for a 6-7 months in the nursery) have been consistently used as a morphological grading standards for seedlings ready for planting. In the application of hardening treatments with water, grading standards should not be disregarded, rather water treatments should produce seedlings that cut across these minimum target standards and at the same time allow for greater vigor 
and tolerance of seedlings. The variations in the increment of above ground parts of seedlings is shown in Figure 1.

The variation in the growth of root parts is shown in Fig. 2. Water stress treatment induced the production of more lateral roots but smaller in diameter compared to those that received regular watering. Roots produced by water stressed seedlings are more compact with a more fibrous root system. Seedlings with more lateral roots have been found growing better in the field than those having fewer lateral roots (Carandang, 1994). Basic survival requires that a seedling root system be large enough to sustain water absorption in amounts that cover transpiration losses. The formation of more lateral roots in water stress seedlings can be an adaptive mechanism for stress regulation associated with the capacity of roots to take up nutrients and water. In addition, water stressed seedlings display a more balance root-shoot ratio indicating the role of water in promoting a more favorable root-shoot development. Mean comparison showed significant correlation between root-shoot ratios and root biomass. The most ideal root-shoot ratio is 0.5 to 1 for forest tree seedlings; that is root measurement must be at least half or equal to the shoots (Moony et al. 1991). The most appropriate root-shoot ratio closest to 1 are those obtained by moderate and severely stressed seedlings. On the other hand, root biomass is the sum total of all lateral roots including the fibrous roots attached to it. In the plantation it is reasonable to assume that a larger root biomass increases water uptake and higher root growth potential (Rose et al. 1990). Earlier studies have shown that, water stress generally increases the proportion of biomass to roots as a result of altered source-sink relation in favor of the roots (Sharpe and Davis, 1979). The result of this study may show that water stress conditioning is one possible pathway for increasing the volume of root biomass conferring better water and nutrient absorption and survival potential of seedlings when planted in the open field. The variation in root architecture of seedlings grown in large pots is shown in Figure 2 and 3. The photograph in Figure 4 shows clearly the variations in root mass in seedlings subjected to three types of water treatments. It is apparent that seedlings in severely stressed condition obtained the biggest root mass followed by moderately stressed and unstressed condition in decreasing order.

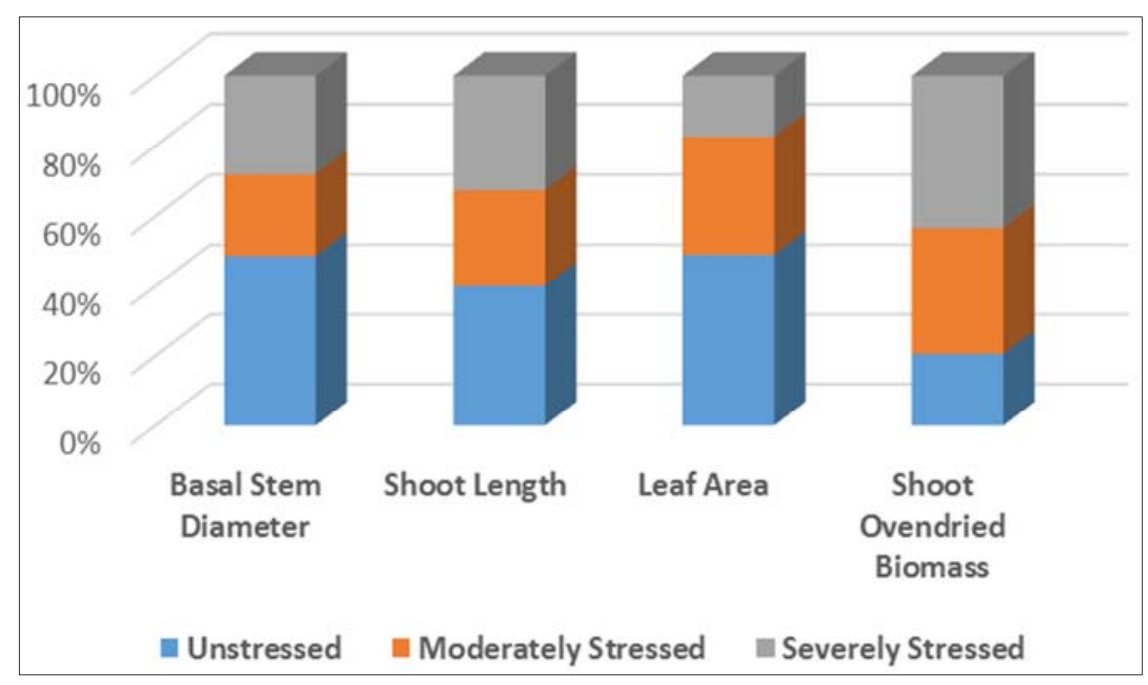

Figure 2. Increment in the shoot parts of GMELINA arborea Roxb. Sppeedlings as influenced by three levels of water treatments.

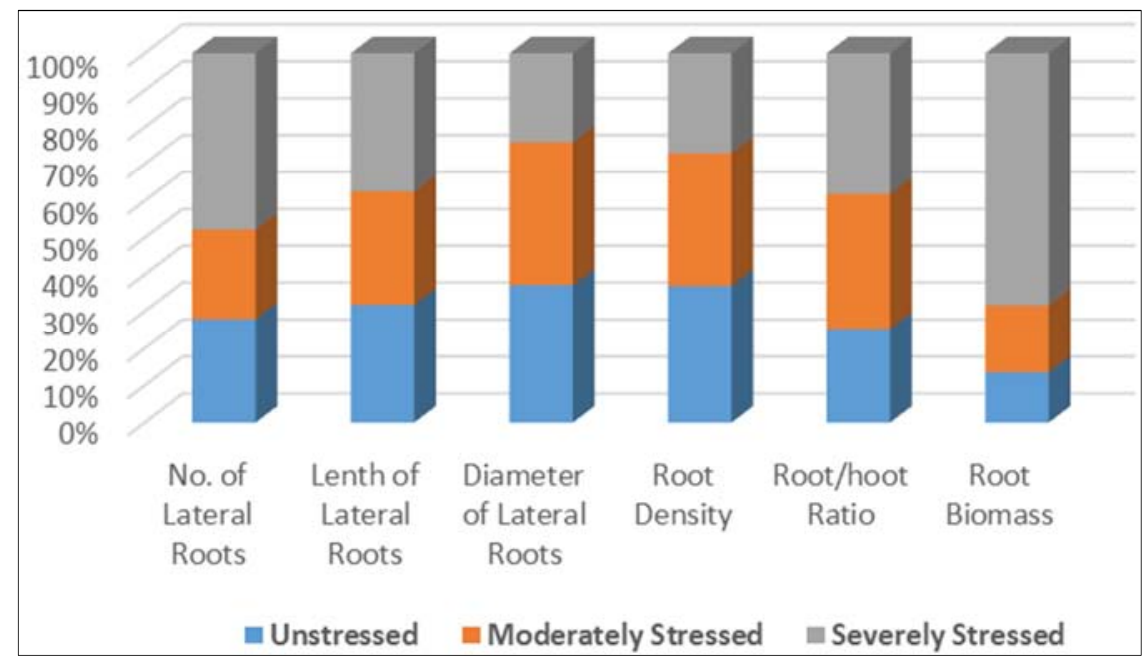

Figure 3. Increment in root parts of Gmelina arborea roxb. as influenced by three levels of water treatments. 


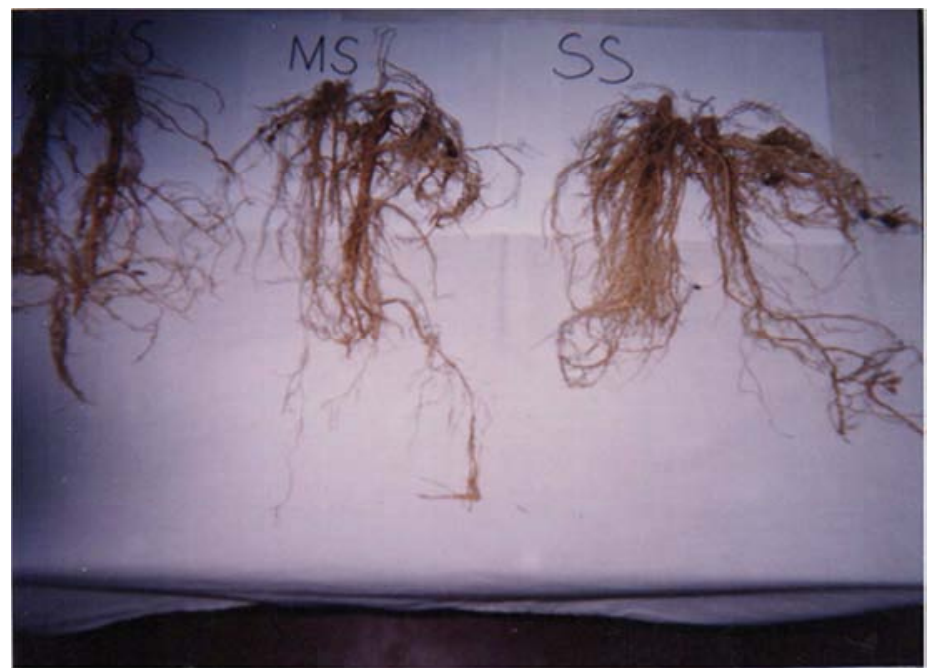

Figure 4. Variation in root architecture of yemane seedlings grown in large pots as Influenced by three levels of water treatments (US-Unstressed, MSModerately stressed, SS-Severely stressed) Growth Processes in Roots Isolated in Small Pots.

The length of lateral roots and root density of roots isolated in small pots were measured to determine possible effects of localized water treatments on root growth behavior. It was predicted that roots isolated in small pots will respond independently to water treatment without any influence from the main root system. Treatment mean comparison did not show any significant variation in the length of lateral roots but differ significantly in terms of root density.

The apparently bigger root density of moderate and severely stressed lateral roots isolated in small pots points to the beneficial role of water stress in inducing localize root development without any influence from the main root system. Localize root development mimics the actual condition of extending roots passing through depletion zones beneath the soil surface. Roots passing through this stress zones has to increase root density to increase its chances of accessing growth limiting resources.

In relation to the usefulness of water treatment as a tool in manipulating shoot and root morphology of yemane seedlings, nursery operation should underscore the production of vigorous and healthy seedlings that meets quality standards. In doing this, the early phase of nursery operation preferably the first 3-4 months should be devoted to promoting the rapid growth and development of seedlings to meet the appropriate diameter (pencil size) and height (30 $\mathrm{cm})$ standards. If the whole nursery cycle takes 8 months, the last 4-5 months should be the hardening phase to exploit the beneficial effect of water stress treatments in conferring the desired seedling quality. Seedling quality can be express in terms of morphology and physiology and this can be done by controlling the growth of shoot and root parts. Under standard planting condition where moisture stress can be low, taller seedlings with fewer and larger lateral roots can be used. However, when planting is expected to be done on suboptimal site conditions where moisture tend to become limiting it would be more fitting to produced seedlings that are shorter but with bigger root biomass. It is also more practical to manually transport shorter seedlings with minimal disturbances on its canopy and root system especially in hilly to mountainous plantation areas. Under these growth limiting conditions, the imposition of water stress treatments to produce shorter seedlings has practical relevance to nursery managers.

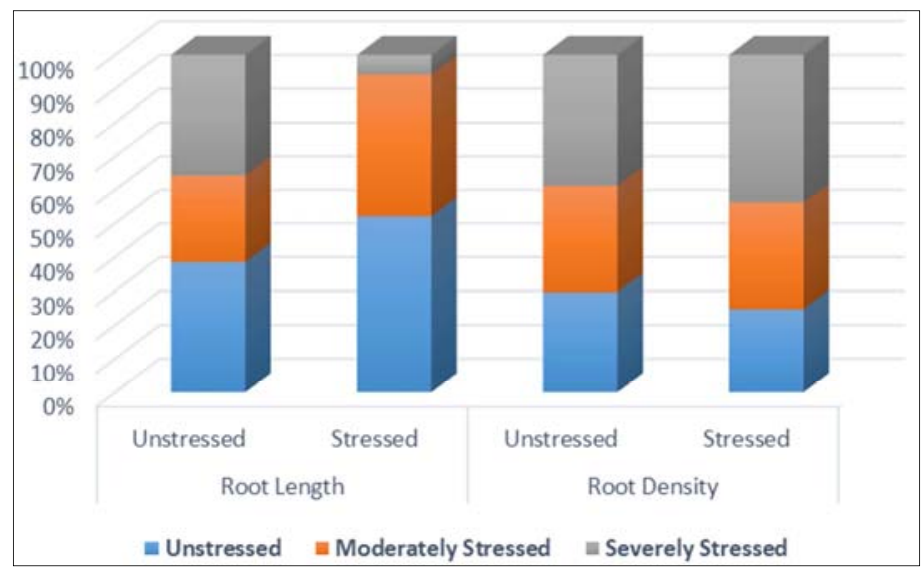

Figure 5. Increment in roots isolated in small pots subjected to unstressed and water stressed condition. 


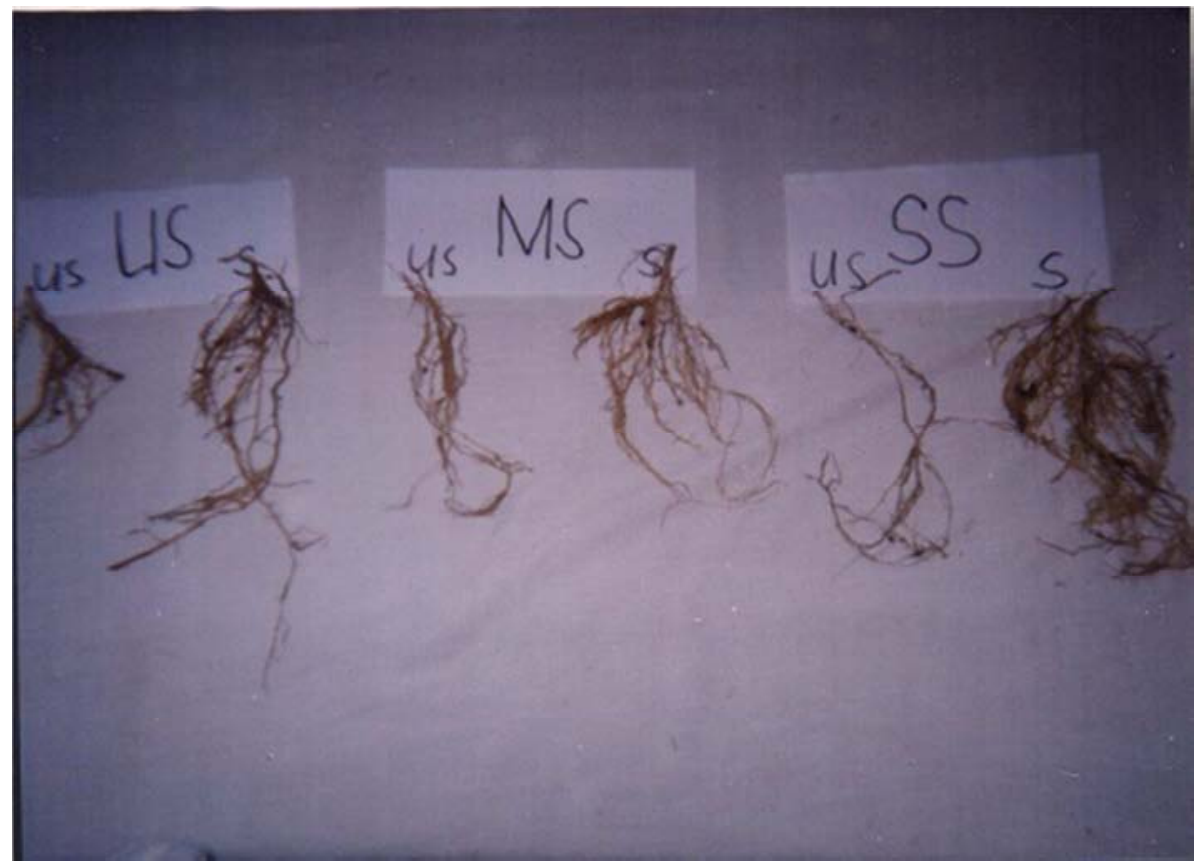

Figure 6. Variations in root architecture of roots isolated in small pots subjected to unstressed and stressed condition.

Carbohydrate content of plant parts in large pots

The carbohydrate content of leaves, stem and roots in the form of starches (\%) and sugars (\%) were obtained to determine the effect of water treatment on the partitioning of these products to different plant parts. The assumption is that water stress may trigger a shift in carbon allocation from the leaves to the roots. The results in Fig. 7 and 8 seem to support these findings indicating a higher concentration of assimilates in leaves, stem and roots of seedlings in unstressed condition and decline as treatment moves to moderate and severely stress condition. The concomitant increase in carbon partitioning to moderate and severely stressed parts is indicative of the shift in carbon partitioning to these parts as an impact of water stress treatment. Schurr and Jhanke (1991) observed that water stress alter sourcesink relations favoring root export. Similarly, Hsiao and
Acevedo (1974) provided evidence that water stress can stimulate root growth in drought resistant species and the effect is likely to occur at levels of water deficit sufficient to significantly reduce shoot growth but not carbon dioxide assimilation. Over the entire nursery cycle of 6-8 months for yemane seedlings, the first 3-4 months should be focused on the normal development of both root and shoot parts by the provision of unrestricted water to seedlings. The other half of the nursery cycle should be allocated to the hardening phase to induce some changes in the shoot and root part of seedlings. The possibility of altering source-sink relation to favor the development of root parts is a good justification for the application of water stress hardening treatment in the production of containerized seedlings. The carbohydrate content of plant parts in large pots is shown in Figure 7 and small pots in Figure 8.

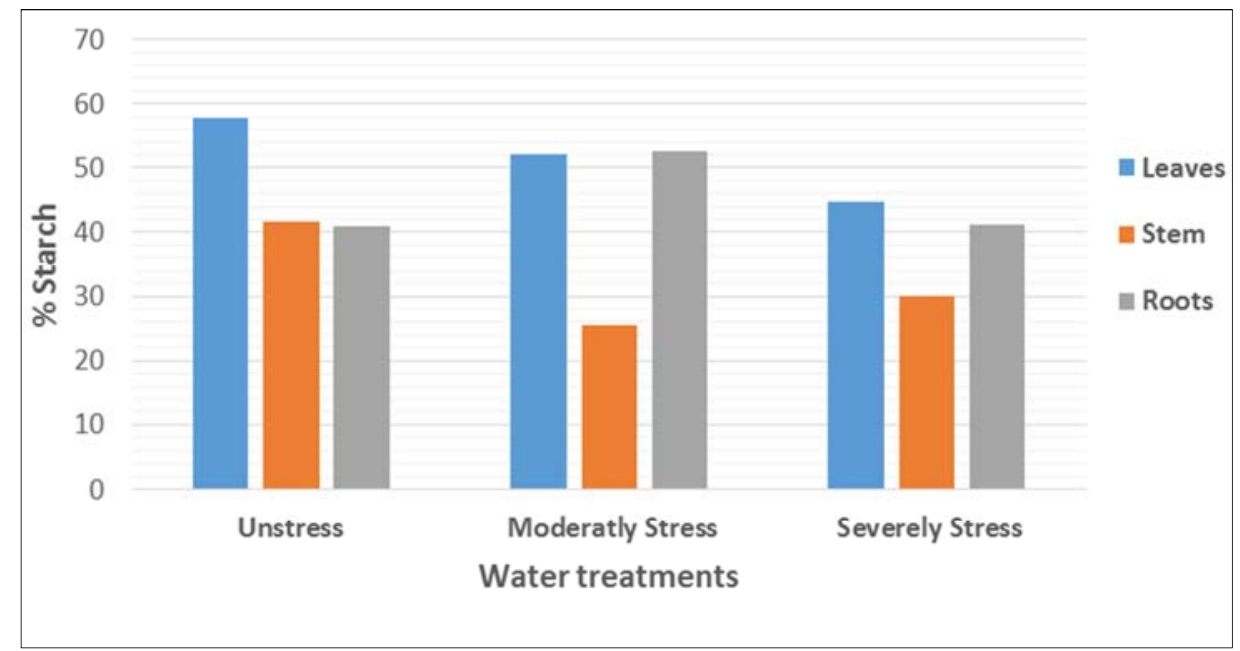

Figure 7. Carbohydrate (starch) content of leaves, stem and roots of seedling grown in large pots subjected to three levels of water treatments. 


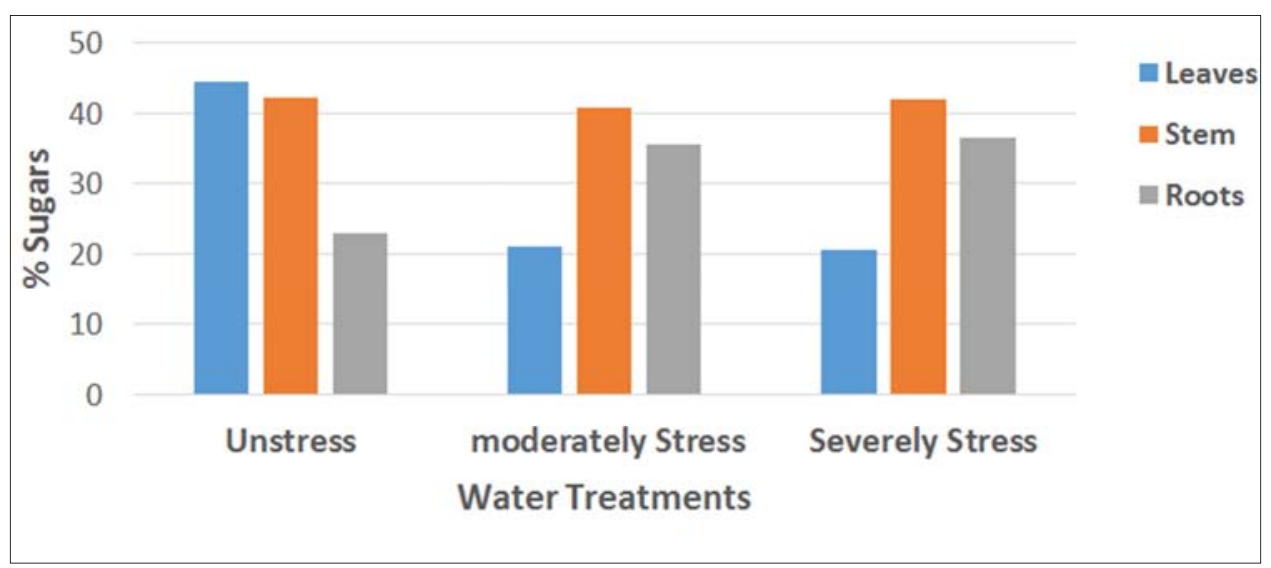

Figure 8. Carbohydrate (Sugar) content of leaves, stem and roots of seedling grown in small pots subjected to three levels of water treatments.

Effects of Water Treatments on Root-Shoot Growth Relations.

In the analysis of root-shoot growth relations in response to stress, the whole plant can be divided into leaves, stem and roots making up the three major but arbitrary divisions (Mooney et al. 1991). Leaves, stem and roots act as one physiological unit receiving environmental stimuli and respond in an integrated manner to control the development of the whole plant. Plants grow in many distinctive ways and across the range of normal growth processes, plant attain a balance growth according to the dictate of specific selection pressures. Under conditions of resource scarcity, plants respond to stress by altering normal growth processes and evolve new traits to be able to adopt to that particular stress. It is believed that leaf function and carbon allocation patterns are the two factors that integrate overall plant responses to stress (Friend et al. 1994).

The response of roots and shoots to water treatment is difficult to see in the nursery because physiological processes occur at the cellular level. It is rather the outward morphological changes exhibited by plants that shows what is happening at the physiological level. The combined effects of water treatment on individual plant parts would cause a decrease or increase in either of the root and shoot parts, respectively.

Regular watering of seedlings (unstressed condition) induced apical dominance in yemane seedlings and the production of bigger diameter lateral roots. In contrast, seedlings grown in water stressed environment responded by reducing the size of above ground parts and increasing the size of its root portion. Specifically, water stress induced the production of shorter shoots, smaller leaf area, smaller basal stem diameter, longer lateral roots, more numerous of lateral roots, bigger root-shoot ratio, bigger root biomass and a more fibrous root system. These changes in root and shoot architecture can be considered as compensatory growth responses between roots and shoot parts in response to water stress treatments. These modifications has particular relevance to the survival of seedlings when out-planted in the open field. Stem diameter and seedling height had been used as the traditional indices predicting the survival of seedlings after transplanting. Mexal and Landis (1990) averred that stem diameter is a good predictor of field survival and longterm tree volume growth. Seedling height was not correlated with seedling survival but known to be a good predictor of growth after transplanting. However, there is a need to correlate these two parameters with physiological indices of performance especially so when seedlings are to be outplanted in high stress environment. Water hardening treatment has the tremendous potential to modify seedling morphology to improve seedling performance and planting job in the open field.

\section{Conclusion and Recommendation}

The study provided evidences for the practice of using water as a hardening tool in the nursery. The study clearly showed that water can be use to modify seedling morphology and architecture which has particular practical application for improving seedling quality and planting job. The production of shorter seedlings with smaller canopies may provide the necessary mobility in hilly to mountainous terrains.

In physiological terms, seedlings with smaller canopies use lesser water than bigger ones. Basic survival requires that seedlings should have a larger root system but smaller canopies. The larger root system supply enough water in amounts that cover transpiration losses. The rate of transpiration is associated with the size of the root system, leaf area and the condition of the planting environment.

In the tropical regions of the world where two climatic seasons prevail such as wet and dry, outplanting activities is usually done during the wet months. However, with the advent of climate change, there are times when out-planting cut across intervening dry months and this affects the growth and survival of newly planted seedlings. When this occurs, root growth is limited by low soil moisture and the seedling is dependent on its nursery cultured root and shoot system for water and nutrient uptake. During this period the sizes of both the root and shoot is critical in the absorption of much needed moisture in the soil until new roots are formed. The larger root system and smaller canopies induced by water stress treatments provide a balance between water absorption 
and transpiration. A seedling with bigger root system but smaller canopy has more competitive advantage for survival than seedlings with relatively smaller root system but with larger canopies.

In the production of containerized seedlings, it is necessary that seedlings moving out of the nursery should meet appropriate morphological grading standard in terms of height $(30 \mathrm{~cm})$ and diameter (pencil size). Nursery operation for most tropical forest trees may last for 6-8 months depending on species. In this regard, the first few months of the nursery tending phase lasting from 3-5 months can be used to promote the apical dominance of seedlings to meet the appropriate sizes. The second and last phase of the nursery cycle which may last for 3-4 months be use as the hardening phase to improve seedling physiology.

For the practical application of water stress treatments, the protocol that was tested in some nursery studies (Friend et al. 1994, Seiler and Johnson, 1985) is to apply water when seedlings show visible mid-day symptoms of wilting. However, water application must be done on time to prevent stress injury to seedlings. Seedlings are usually sensitive to water stress due to their young and immature root system. Fostering root development for absorptive capacity immediately after outplanting especially in dry and degraded sites should be of paramount importance during the nursery tending phase. This can be done by using water as a hardening tool in the nursery.

As shown in this study, the four months application of water stress treatments is more than enough for Gmelina arborea roxb seedlings to produce the desired morphological changes in both root and shoot parts and these can be tried for other forest tree species.

\section{Acknowledgement}

I would like to acknowledge with gratitude the Ifugao State University, Ifugao, Philippines for the time and support given to me in conducting the research project. My students who had been instrumental in the layout and establishment of the plots and the layout of the small greenhouse that was used in this field experiment. To the Philippines Department of Environment and Natural Resources-Ifugao (DENRIfugao) for providing the seedlings that was used in this study.

\section{References}

[1] Auge, R. M., Shaekel, K. A. and R. L. Wample. 1986. Osmotic Adjustment in Leaves of VA Mycorrhizal and Nonmycorrhizal Rose Plants in Response to Drought Stress. Plant Physio. Vol. 82.

[2] Begg, J. E. 1980. Morphological Adaptation of leaves to water stress. In Adaptation of Plants to Water and high Temperature Stress. Wiley Interscience, New York.
[3] Carandang, W. M. 1994. Lateral Root Development and Seedling Performance of Large Leaf Mahogany. Ph. D Dissertation, UPLB, Laguna.

[4] Friend A. L., Coleman, M. D. and J. G. Isebrand. 1994. Carbon Allocation to Root and Shoot Systems. In Biology of Adventitious Root Formation. Plenum Press, New York.

[5] Friend, A. L., Eide, M. R. and T. M. Hinkley. 1990. Nitrogen Stress Alters Root Proliferation in Douglas Fir Seedlings. Can. Journal of For. Res. Vol. 20.

[6] Hsiao, T. C. and K. J. Acebedo. 1974. Agricultural Meteorology. Vol. 14.

[7] Mexal, J. G. and T. D. Landis. 1990. Target Seedling Concept: Height and Diameter. In Target Seedling Symposium: Proceeding, Combined Meetings of the Western Forest Nursery Associations. General Technical Report 200, USDA, Roseburg, Oregon.

[8] Koro, R. L., Kirsbaum, M. U. F., Farquhar, G. D. and M. Jeffreys. 1999. Effects of Water Status and Soil Fertility on Cisotope Signature in Pinus radiate. Tree Physio. Vol. 19.

[9] Mooney, H. A., Winner, E. W, Pell, E. J and E. Chu. 1991. Response of Plant to Multiple Stresses. Academic Press, New York.

[10] Osonobi, 0. and F. E. Fasehun. 1987. Adaptation to Soil Drying in Woody Seedlings of African Locust Bean. Tree Physio. Vol. 3.

[11] Parker, J. 1979. Drought Resistance Mechanism. In water Deficits and Plant Growth. (T. T. Kowslowski, ed) Academic Press, New York.

[12] Pereira, J. S. and M. M. Chaves. 1993. Plant Water Deficits in Mediterranean Ecosystems. In Water Deficits. Bios Scientific Publishers, Oxford.

[13] Rose, R., Carlson, W. C. and P. Morgan. 1990. The Target Seedling Concept. In Target Seedling Symposium. Gen. Tech. Report, USDA, Roseburg, Oregon.

[14] Seiler, J. R. and J. D. Johnson. 1985. Photosynthesis and Transpiration of Loblolly Pine Seedlings As Influenced by Moisture Stress Conditioning. Forest Science. Vol. 31. No. 3 Society of American Foresters.

[15] Zhang, J. W., Marshall, J. D. and L. Finus. 1996. Correlated Population Differences in Dry Matter Accumulation, Allocation and Water Use Efficiency in 3 Sympatric Conifer Species. For. Sci. Vol. 42.

[16] Sharp, R. E. and W. J. Davies. 1979. Solute Regulation and Growth by Roots and Shoots of Water Stress Maize Plants. Planta Vol. 47.

[17] Rose, R, Carlson, W. C. and P. Morgan. 1990. The Target Seedling Concept. In Target Seedling Symposium. General Technical Report, USDA, Roseburg, Oregon.

[18] Schurr, U. and S. Jhanke. 1991. Effects of Water Stress and Rapid Changes in Sink Water Potential on Phloem Transport in Ricinus. In Recent Advances in Phloem Transport and Assimilate Compartmentalization. Quest Edition, Press Academique, Nantes. 